\title{
O OLHAR DO PEDAGOGO SOBRE A EDUCAÇÃO FÍSICA NOS ANOS INICIAIS DO ENSINO FUNDAMENTAL
}

DOI: $105902 / 0102830820547$

Data de submissão: 28-11-2015

Data de Aceite: 11-10-2016

Bruna Mendonça

Universidade Federal de Santa Maria brunabmendonca@gmail.com

Leandra Costa da Costa

Universidade Federal de Santa Maria

Icostadacosta@hotmail.com

Resumo: O objetivo deste trabalho é apresentar, através de um estudo de caso, discussões realizadas durante a disciplina de Educação Física e Movimento Humano do curso de Pedagogia Licenciatura Plena/UFSM, a partir de observações realizadas nos Anos Iniciais de uma escola da rede pública do município de Santa Maria/RS que possibilitaram identificar a estrutura das aulas de Educação Física, possibilitando reflexões sobre o planejamento e a prática pedagógica nas aulas de Educação Física. Os dados permitiram visualizar que nem sempre há um planejamento consistente para as aulas o que gera dificuldades de aprendizagem dos conteúdos.

Palavras-chave: Educação Física. Prática Pedagógica. Anos Iniciais. 


\section{INTRODUÇÃO}

O processo de ensino e aprendizagem do aluno durante seu percurso escolar acontece por meio do contato direto ou a aproximação do objetivo que se queira trabalhar durante o processo educativo, sendo assim a aprendizagem também acontece por meio das interações e associações (VYGOTSKY, 1991), vinculadas ao objetivo proposto. Diante disso, o professor pedagogo necessita de um planejamento que vise abarcar outras áreas de conhecimento vinculadas ao contexto sócio-histórico do aluno. Tendo em vista o processo de ensino e aprendizagem em relação a área da Educação Física, o mesmo exige que o professor desenvolva ações que estejam associadas às possibilidades corporais e ao contexto social do aluno.

Para um planejamento que vise abranger todos os benefícios e possibilidades de aprendizagem na Educação Física é essencial que o professor tenha conhecimento do conceito de Educação Física, assim como as bases teóricas que fundamentam esta área do saber. Estes estudos permitem que o professor desconstrua a ideia de que a Educação Física é somente uma atividade esportiva associada aos movimentos perfeccionistas tendo a competição como a finalidade principal.

Tomamos como base alguns estudos teóricos que pautam a discussão sobre a prática pedagógica da Educação Física no contexto escolar. Entre elas, está o movimento humano que Kunz (2000) define como uma concepção de movimento que ultrapassa o deslocamento do corpo no espaço considerando que o mesmo realize o movimento a partir das significações culturais. O referido autor questiona as vertentes mecanicistas onde o corpo encontra-se separado do mundo. Para tanto, (KUNZ, 2000) coloca a ideia de que o movimento do corpo humano é inseparável do mundo do qual pertence, sendo o ambiente o grande problematizador dessa ação.

Segundo os Parâmetros Curriculares Nacionais - PCN's (1997) referente à disciplina de Educação Física é possível verificar que a mesma permite a tematização das mais diversas culturas e possibilita assim uma variada combinação de manifestações culturais. Para que isso aconteça, é importante destacar a busca por conhecimentos prévios sobre o assunto tratado, definindo quais são os princípios da Educação Física no contexto escolar quanto à Educação Infantil e os Anos Iniciais. Cabendo ao educador a sensibilidade de 
compreender os conhecimentos corporais do aluno, bem como suas limitações.

Segundo os Parâmetros Curriculares Nacionais:

O processo de ensino e aprendizagem em Educação Física, portanto, não se restringe ao simples exercício de certas habilidades e destrezas, mas sim de capacitar o indivíduo a refletir sobre suas possibilidades corporais e, com autonomia, exercê-las de maneira social e culturalmente significativa e adequada (PCN's, 1997. p. 27).

Para tanto, o processo de ensino e aprendizagem juntamente com as abordagens pedagógicas são essenciais para que seja possível delinear a qualidade do trabalho docente no exercício das práticas pedagógicas na Educação Física (AZEVEDO E SHIGUNOV, 2000), permitindo então, que o professor tenha clareza na construção de seus planejamentos ao desenvolver propostas vinculadas a cultura de movimento.

É importante ainda que o professor tenha um conhecimento mais aprofundado a respeito das abordagens pedagógicas da Educação Física que vivem entre debates, discussões e conflitos epistemológicos primando ora por uma realidade social específica ou sugerindo transformações de caráter emancipatório para a sociedade. As abordagens podem ser dividas em críticas e não críticas: as Aulas Abertas; Saúde Renovada; Construtivistainteracionista; Crítico-emancipatória; Crítico-superadora; Desenvolvimentista; Educação Física Plural; Humanista; Psicomotricista e Sistêmica (AZEVEDO E SHIGUNOV, 2000).

A Educação Física ao longo de sua trajetória passou e ainda passa por influências sócio-histórico-culturais que determinam concepções e tendências metodológicas sobre o currículo escolar. Nesse sentido, a Educação Física a partir dos anos 80 passa a ser pensada em outros modelos, contrapondo aquela do Governo Militar da década de 70 que objetivava a formação de um "corpo forte", focada a atender aos interesses militares do Governo e elevar o nacionalismo por meio do esporte (CASTELLANI FILHO, 1988).

Cada pedagogo possui uma base teórica que dá subsídios para a construção de suas práticas educativas em relação à Educação Física. A intencionalidade desta reflexão está condicionada ao (re) pensar as práticas pedagógicas que estão sendo desenvolvidas com os alunos nos Anos Iniciais do Ensino Fundamental.

O trabalho da Educação Física está direcionado no intuito de promover a saúde e a cultura de movimento dos alunos nos espaços escolares e não escolares, devido ao fato do professor tematizar em sua aula diferentes manifestações culturais propagando o hábito e 
a motivação no que se refere a prática de atividades físicas no seu cotidiano.

Vale ressaltar que para cada etapa da Educação Básica, o professor precisa adaptar suas propostas levando em consideração a especificidade de cada aluno, as capacidades e habilidades. A maneira de como cada sujeito desenvolverá as propostas será distinta, pois cada aluno apresenta limitações e potencialidades em relação à Educação Física. Ao respeitar essas singularidades, o professor juntamente com o aluno desempenha um conjunto de elementos que enriquecem o desenvolvimento dos alunos na apreensão dos conteúdos.

O planejamento do professor terá êxito quando associado a outras áreas de conhecimento, propiciando um olhar atento às singularidades nos diferentes aspectos de desenvolvimento que favoreçam ações e metodologias distintas. Dessa forma, a Lei de Diretrizes e Bases da Educação Nacional - LDBEN (Lei n9394/96) no que tange a Educação Básica afirma no art. ${ }^{\circ} 26$ no $\S 3^{\circ}$ : "A Educação Física, integrada à proposta pedagógica da escola, é componente curricular da Educação Básica, ajustando-se às faixas etárias e às condições da população escolar [...]".

Tendo a Educação Física como objetivo trabalhar as dimensões corporais dos alunos de acordo com a sua faixa etária remete-se a um debate sobre a importância desta modalidade curricular dentro da escola como promotora de desenvolvimento global da criança. Da mesma forma os PCN's da Educação Física (1997) ressaltam que os objetivos da Educação Física estão associados às relações sociais e culturais do aluno, tendo como metodologia os aspectos educacionais mais amplos e conteúdos diversificados.

Não raro, a prática da Educação Física está pautada em atividades físicas repetitivas, as quais têm como objetivo o desenvolvimento da aptidão física. No entanto, com o intuito de desconstruir as ideias errôneas e as ações repetitivas que muitas vezes se desenvolvem nas aulas, e oportunizar outros componentes que qualifiquem as suas propostas educativas, os PCN's mencionam que:

Não basta a repetição de gestos estereotipados, com vistas a automatizá-los e reproduzi-los. É necessário que o aluno se aproprie do processo de construção de conhecimentos relativos ao corpo e ao movimento e construa uma possibilidade autônoma de utilização de seu potencial gestual (BRASIL, 1997 p.27). 
Durante a leitura dos aportes teóricos sobre a Educação Física e Educação Básica, bem como a legislação pertinente a área, percebe-se que há uma visão da Educação Física, como sendo sinônimo de qualidade na Educação e um direito das crianças em desenvolver as práticas corporais na escola.

\section{METODOLOGIA}

O presente estudo se estrutura em uma abordagem qualitativa, elencando-se dados descritivos e empregando diferentes concepções filosóficas, estratégias de investigação, método de coleta, análises e interpretação dos dados (CRESWELL, 2010).

Dentre as pesquisas qualitativas, optou-se pelo estudo de caso que, para Chizzotti (1998, p. 102), "é uma caracterização abrangente para designar uma diversidade de pesquisas que coletam e registram dados de um caso particular ou de vários casos a fim de organizar um relatório ordenado e crítico de uma experiência".

Este estudo investigativo estrutura-se nas atividades desenvolvidas ao longo da disciplina de Educação Física e Movimento Humano desenvolvida no $7^{\circ}$ semestre do curso de Pedagogia Licenciatura Plena - Diurno da Universidade Federal de Santa Maria/ UFSM no primeiro semestre de 2014, cujo objetivo estava pautado em conhecer, planejar, executar e avaliar atividades de movimento corporal para crianças inseridas no trabalho de escolarização, identificando o significado e as contribuições destas como processo educativo.

Para alcançar esse objetivo primeiramente foram realizadas três observações das aulas de Educação Física no intuito de propiciar uma apreensão de como estavam sendo constituídas as aulas, planejadas e orientadas. Dessa forma, foi escolhida uma turma do $3^{\circ}$ ano do Ensino Fundamental da Rede Pública de Ensino do Município de Santa Maria, RS. A turma observada possuía 23 alunos com a faixa etária variando entre oito a nove anos, composta de 13 meninos e 10 meninas.

Para as observações neste contexto foi disponibilizado um roteiro de observação, onde continha os seguintes elementos: (a) a fundamentação sobre a Educação Física nos Anos Iniciais, (b) a fundamentação dos planejamentos que o professor desenvolvia nas aulas, e (c) reflexões realizadas a partir da prática. 
No primeiro momento a disciplina esteve voltada para a discussão sobre a importância da Educação Física nos Anos Iniciais, que contribui expressivamente no reconhecimento corporal dos alunos, além do mesmo ter a oportunidade de estar conhecendo seus próprios limites corporais e a valorização das atividades físicas para a sua vida. O segundo momento se estruturou nos estudos e a apresentação dos elementos e os pressupostos das atividades elaboradas pelo professor nas aulas de Educação Física, como a utilização de materiais e outros instrumentos que venham a contribuir durante as aulas, bem como as abordagens teóricas metodológicas que o educador se utiliza ao construir suas práticas. E por fim, o terceiro ponto que é o comportamento do aluno em relação às expressões corporais, interação entre professor e colegas e a efetiva participação nas atividades que são desenvolvidas durante as aulas.

Ao final da disciplina, considerando os aportes teóricos desenvolvidos e as observações ocorridas no contexto escolar, foi realizado um seminário com discussões referentes ao movimento humano, a disciplina contribuiu também na construção de um portfólio que apresentasse um roteiro de atividades desenvolvidas ao longo da disciplina e a construção de materiais como: peteca, bilboquê, obstáculos, jogos com cordas, bambolê, sapata móvel, vai e vem, bolinhas de meia, saquinhos de areia e elástico.

Para cada um dos respectivos materiais utilizados durante as aulas práticas da disciplina, a turma elaborou planos de aula específicos, os quais estavam estruturados: a faixa etária, objetivos, justificativa, descrição, método e avaliação.

Além, do desenvolvimento dos planos de aula mencionados que se constituíram em atividades práticas, o portfólio apresentou propostas direcionadas aos Anos Iniciais do Ensino Fundamental. As atividades foram desenvolvidas pela turma, com o objetivo de enriquecer os planejamentos, bem como, oportunizar maior amplitude nos estudos da área da Educação Física tendo em vista o desenvolvimento integral da criança.

\section{A EDUCAÇÃO FÍSICA NOS ANOS INICIAIS E SEUS DESAFIOS}

Os alunos se desenvolvem na escola a partir de vivências e experiências a partir do Brincar que envolve a exploração do seu próprio corpo e do ambiente. Essas mesmas 
experiências possibilitam uma variedade de movimentos e conhecimentos acerca dos jogos e brincadeiras. Para tanto, os conhecimentos vivenciados pelas crianças são importantes, por que através desses elementos o professor desenvolve novas formas de aprendizagem.

Os PCN's contribuem para a organização dos conteúdos e objetivos que se dividem em primeiro, segundo e terceiro ciclo, elencando especificidades e abordagens pedagógicas, que estão diretamente associadas ao ensino e aprendizagem, bem como condições culturais.

No primeiro ciclo os (PCN's, 1997) abordam uma série de conteúdos, que apresentam como base as dimensões conceituais, procedimentais e atitudinais, ressaltando ainda que esses respectivos conteúdos estão diretamente associados aos objetivos da Educação Física, segundo os PCN's da Educação Física (1997) está mencionado que:

\footnotetext{
Participar de diferentes atividades corporais, procurando adotar uma atitude cooperativa e solidária, sem discriminar os colegas pelo desempenho ou por razões sociais, físicas, sexuais ou culturais; Conhecer algumas de suas possibilidades e limitações corporais de forma a poder estabelecer algumas metas pessoais (qualitativas e quantitativas); Conhecer, valorizar, apreciar e desfrutar de algumas das diferentes manifestações de cultura corporal presentes no cotidiano; e Organizar autonomamente alguns jogos, brincadeiras ou outras atividades corporais simples (BRASIL.1997, p.47).
}

Dessa forma, a Educação Física deve oportunizar aos alunos o desenvolvimento de suas potencialidades, bem como possibilitar um maior desenvolvimento do movimento, porém são muitos os desafios que são encontrados no contexto escolar, cabendo a gestão educacional como um todo, juntamente com os profissionais da educação, promover uma reflexão pedagógica acerca do desenvolvimento infantil concomitante com as atividades que trabalham com a cultura de movimento, tão presente nos Anos Iniciais. Wallon (1995, p. 96), ressalva que a prática pedagógica como instrumento "suscita uma prática que atenda às necessidades da criança nos planos afetivo, cognitivo e motor e que promova o seu desenvolvimento em todos os níveis".

Faz-se necessário o debate da prática pedagógica e dos aspectos conceituais na construção de planejamentos para as aulas de Educação Física. A discussão referente a prática pedagógica, auxilia nas reflexões das atividades desenvolvidas pelo professor nas aulas o que torna o contexto educativo mais prazeroso para todos os envolvidos. Veiga(1989, 
p.16) apresenta, em linha geral, que a "prática pedagógica é uma dimensão da prática social que pressupõe a relação teoria-prática, e é essencialmente nosso dever, como educadores, a busca de condições necessárias à sua realização". Para tanto, a prática pedagógica do professor é formada a partir dos estudos teóricos e principalmente com a relação da teoria e a prática, ambos os elementos importantes no contexto escolar. Cabendo assim, ao professor associar esses conhecimentos juntamente com os planejamentos diários.

\section{- planejamento e a pRática pedagógica das aulas de EDUCAÇÃO FÍSICA}

A escola em que foram realizadas as observações das aulas de Educação Física, possuía em torno de 23 alunos e cada aula teve uma duração de 45 minutos.

$\mathrm{Na}$ primeira aula observada o professor utilizou o espaço da quadra esportiva, onde desenvolveu atividades em grupo utilizando como materiais a bola e cordas para realizar os jogos; também foi realizada uma brincadeira chamada de "verdade ou mentira". A brincadeira foi realizada da seguinte forma: duas linhas dispostas frente a frente, uma de meninas e outra de meninos. Uma das linhas representava verdade e a outra a mentira. $\mathrm{O}$ professor dirigia a brincadeira mencionando uma frase que se remetia a um acontecimento, ou seja, verdade ou mentira sobre um aluno (a) que fazia parte de uma das linhas, por exemplo: O João gosta de sorvete (o aluno deveria confirmar ou negar a pergunta feita), caso fosse verdade a linha que representava a verdade teria que sair para pegar a linha constituída pelos alunos que representavam a mentira, caso fosse mentira aconteceria o inverso. É importante destacar que foi possível verificar que enquanto os meninos jogavam bola as meninas pulavam corda ou arremessavam a bola na cesta de basquete que ficava no lado de fora da quadra.

No segundo dia de observação a aula também foi desenvolvida na quadra esportiva onde se desenvolveram as seguintes brincadeiras. A brincadeira "Pega-pega corrente" que se organizou da seguinte maneira: Foram formadas duplas e trios que seriam responsáveis de pegar o restante da turma, quando um aluno (a) era pego, esse deveria se inserir na dupla ou trio e assim por diante. Para poder pegar os colegas que estavam fugindo os alunos (as) 
que formavam os trios e duplas obrigatoriamente deveriam estar de mãos dadas. A outra brincadeira que fez parte dessa aula era denominada de "árvore venenosa" e foi organizada da seguinte maneira: quatro alunos ficavam posicionados no círculo maior da quadra e os demais alunos tentavam atravessar de um lado para o outro passando pelo círculo evitando de serem pegos. Os alunos (as) que se encontravam no círculo, deveriam tentar pegar os demais colegas e os que tinham sido pegos deveriam ficar dentro do círculo e auxiliar, porém não poderiam sair do local. Foi realizada também uma atividade que envolvia corrida individual, os alunos (as) estavam dispostos em duas colunas, uma constituída por meninas e outra por meninos. As duas colunas competiram, buscando verificar qual integrante de cada coluna iria chegar primeiro no ponto marcado como chegada, quem terminasse o percurso primeiro vencia a atividade.

Depois de desenvolvidas as atividades descritas anteriormente os alunos (as) ficaram na quadra brincando livremente até a hora da saída. Outro ponto observado é uma possível não organização do contexto da aula, que pode acarretar em dispersões e até mesmo brigas. Para um observador externo pode parecer que nada faz sentido em uma aula ou atividade, mas para os protagonistas do contexto, ou seja, para os alunos aquele momento, que parece uma confusão generalizada, é carregado de sentidos e significados. Portanto, é importante que o professor organize esse contexto desenvolvendo assim sua proposta pedagógica.

Na organização do contexto escolar Wallon (1995, p.100) evidencia que "o ambiente é o campo sobre a qual a criança aplica as condutas de que dispõe, ao mesmo tempo, é dele que retira os recursos para sua ação". Mas, para que ocorra a organização desse contexto, bem como, a participação efetiva do alunado nas atividades, é importante que esses elementos estejam contemplados no planejamento.

É relevante considerar que o planejamento é fundamental no desenvolvimento das ações e nas práticas pedagógicas no decorrer das aulas, pois segundo Libâneo (2002, p.222) "O planejamento é um processo de racionalização, organização e coordenação da ação docente, articulando a atividade escolar e a problemática do contexto social".

Outro ponto que merece ser destacado foi o distanciamento do professor com os alunos, e suas intervenções, essa consistia basicamente ao ato de chamar a atenção com 
movimentos bruscos durante alguns momentos. O afastamento do professor em relação à turma se refletia significativamente na dispersão dos alunos por meio da desorientação das atividades na quadra.

Emalguns questionamentos feitos aos alunos foi possível perceber o desconhecimento sobre conteúdos específicos da Educação Física, como por exemplo, o que é futebol e suas modalidades como o futsal e futebol sete.

Portanto, o que se percebeu durante as observações foi a falta ou quase inexistência de uma metodologia e planejamento de aula, não possibilitando verificar um desenvolvimento de habilidades motoras para os alunos. O movimento na Educação Física está constituído na maneira como o corpo recebe e reage em cada ação, porém as duas observações realizadas não possibilitaram a verificação de finalidades pedagógicas as quais contemplam os objetivos elencados pelos PCN's da Educação Física (1997).

Nesse sentido é importante também destacar o Coletivo de Autores (1992, p.62):

Os conteúdos selecionados, organizados e sistematizados devem promover uma concepção científica de mundo, a formação de interesses e a manifestação de possibilidades e aptidões para conhecer a natureza e a sociedade. Para isso, o método deve apontar o incremento da atividade criadora e de um sistema de relações sociais entre os homens.

Dessa forma é possível perceber a importância dessa sistematização e organização prévia dos conteúdos pelo professor favorecendo uma perspectiva mais crítica do entendimento da Educação Física e explorando intervenções e relações que se constituem por meio do movimento em todos os momentos das aulas.

\section{REFLEXÕES A PARTIR DA PRÁTICA PEDAGÓGICA}

Quando falamos do comportamento dos alunos nas aulas de Educação Física é possível imaginar, as seguintes situações: os alunos correndo, movimentos rápidos, pulando, gritando, entre outras habilidades corporais que surgem espontaneamente nas relações que se estabelecem. Essas ações são acompanhadas pela ansiedade, euforia e muitas vezes tensão em correr ou pegar os colegas.

González (2006) em seus estudos destaca a importância da estruturação dos 
conteúdos e Zabala (1998) tece considerações pertinentes no que se refere aos métodos de avaliação conceitual, procedimental e atitudinal associados à prática docente. A estruturação e organização dos conteúdos bem como a avaliação também são elementos que assumem destaque e importante papel no ensino/aprendizagem das aulas, pois para muitos alunos as atividades que são desenvolvidas nas aulas de Educação Física ainda apresentam um caráter prático, oriundo dos esportes e competição, que são características oriundas da sociedade e que se refletem no comportamento dos alunos. Para que se efetive uma proposta de Educação Física que venha ao encontro das discussões e abordagens atuais é imprescindível levar em consideração importantes aspectos que permeiam os comportamentos dos alunos (as) como relações inter e intrapessoais que acontecem em todas as aulas, promover o resgate de importantes culturas por meio dos jogos e brincadeiras, considerar o desenvolvimento de cada aluno(a) de acordo com as suas especificidades por meio do movimento e principalmente desenvolver a criticidade de modo que os alunos(as) entendam o seu importante papel na sociedade.

Um dos objetivos delineados para as observações era o de avaliar as atividades de movimento corporal dos alunos durante o desenvolvimento da aula de Educação Física possibilitando verificar que: (a) o comportamento dos alunos estavam direcionados na sua grande parte para as atividades de correr, onde deveriam pegar os colegas em forma de competição, (b) era nítido que as expressões corporais apareciam quando ganhavam a competição ou em momentos de tensão, (c) poucos foram os momentos de interação entre alunos e o professor, (d) a motivação estava presente principalmente nos jogos de corrida e no desenvolvimento da brincadeira "verdade ou mentira" (f) o contato entre os alunos acontecia bruscamente somente no resultado das atividades propostas e (g) não havia sequência nos planejamentos diários e nas propostas de ações ao longo do desenvolvimento das aulas da disciplina.

A falta de contato com os alunos também foi ressaltada, o que resultou no distanciamento e o desinteresse dos alunos em realizar quaisquer atividades corporais, como jogos, brincadeiras e outras que o professor se propunha a fazer. Dessas reflexões evidencia-se que a prática do professor estava estruturada nos princípios da sua compreensão e vivência a respeito da Educação Física na escola. 
Nesse sentido, o diálogo é um instrumento de grande importância para ser utilizado pelos professores, pois pode atuar como uma possibilidade para a resolução de problemas. Para Kunz (1998, p. 41), "saber se comunicar e entender a comunicação dos outros é um processo reflexivo e desencadeia iniciativas do pensamento crítico". Porque é através do diálogo que a maior parte dos professores poderá solucionar as dificuldades enfrentadas, se constituindo como um meio imprescindível para que professores e alunos possam melhor se relacionar e resolver os conflitos existentes no âmbito escolar.

Com base nesse estudo investigativo e a relação do desenvolvimento infantil abordado por Wallon (1995), o meio não é estático e nem homogêneo, mas elemento de transformação juntamente com a criança. Além, da importância do planejamento é preciso conhecer e reconhecer o meio ao qual a criança pertence. O contexto ao qual a criança faz parte, que por sua vez, contribui expressivamente na sua relação com os seus colegas e na escola e também no comportamento mediante as atividades diárias e seu desenvolvimento enquanto sujeito.

Esses elementos, contexto escolar, planejamento das aulas e relações sociais (professor/aluno e aluno/aluno), colaboram tanto na reflexão pedagógica do professor, quanto na construção de problemas e a elaboração de estratégias que visem o desenvolvimento dos alunos no contexto escolar e extraescolar. Desse modo a base teórica consiste em uma fonte de argumentos e um método de construção pedagógica para o desenvolvimento de planejamentos que atendam as especificidades de cada turma no contexto escolar de acordo com a sua respectiva faixa-etária.

\section{CONSIDERAÇÕES FINAIS}

Vivenciamos atualmente um movimento objetivando uma reformulação no sistema educacional do Brasil, que vem acompanhado de debates, movimentos sociais e entidades que disputam os rumos ideológicos por uma concepção de educação que esteja vinculada com um propósito social e político ancorado no contexto social brasileiro.

Mas, neste debate pode-se perceber que apesar do protagonismo no ensino ser dos professores, com formação voltada para o trabalho e desenvolvimento de ações dentro da escola identificando e trabalhando com os desafios colocados pela sociedade é necessário 
que se propicie o protagonismo dos mesmos atuando na construção de políticas públicas. Percebe-se que os rumos da educação e de suas políticas públicas são vinculadas a planos de governo e disputadas por entidades que desconhecem a realidade escolar.

Ao observar o trabalho realizado na Educação Física, visualizamos um descontentamento por parte do alunado, pois não raro encontramos ações educativas pautadas em métodos tradicionais evidenciando distanciamentos entre as relações que se estabelecem entre a prática pedagógica e a realidade dos alunos.

É fundamental que tanto o professor unidocente quanto o professor de Educação Física conheçam o contexto no qual estão inseridos buscando através das abordagens pedagógicas alcançar os interesses de cada aluno, promover o seu desenvolvimento e oportunizar aprendizagens que sejam significativas.

Cabe aos professores, a importante tarefa de estimular e desenvolver a expressão corporal dos alunos, possibilitando a inserção de conteúdos corporais diversificados, pois com esses pode-se construir objetivos essenciais para o seu desenvolvimento, tomando o professor para si o papel de buscar, motivar e evidenciar a importância do "movimento" na vida dos alunos.

Ressalta-se que foram realizadas apenas três observações, o que não permite uma compreensão global do desenvolvimento dessas aulas durante o ano. Portanto, não pretende- se aqui exaurir a temática no que tange ao planejamento e a prática pedagógica, mas atentar para aspectos que podem ser significativos e instigantes para os professores no momento em que elaboram seus planejamentos. Ademais não se almeja criar generalizações a partir de um caso específico, pois cada contexto escolar apresenta suas especificidades culturais e sociais.

Portanto a discussão que realizamos nesse estudo significa o início de um caminho para refletir sobre a importância do planejamento para a prática pedagógica nas aulas de Educação Física, pois aqui foram tratados muito brevemente aspectos que merecem ter estudos mais aprofundados pela riqueza de reflexões que essas temáticas nos sugerem, especialmente como mencionado anteriormente considerando as especificidades de cada escola e o aporte teórico em se tratando deste assunto. 


\section{REFERÊNCIAS BIBLIOGRÁFICAS}

AZEVEDO, E. Souza de; SHIGUNOV, Viktor. Reflexões sobre as abordagens pedagógicas em Educação Física. Kinein, Florianópolis, v. 1, n. 1, set./dez. 2000. Disponível em: <http://boletimef.org/biblioteca/2602/Reflexoes-sobre-as-abordagens-pedagogicasem-Educacao-Fisica>. Acessado em junho de 2014.

BRASIL. Secretaria de Educação Fundamental. Parâmetros Curriculares Nacionais: Educação física /Secretaria de Educação Fundamental. - Brasília:MEC/SEF, 1997. Disponível em: <http://portal.mec.gov.br/seb/arquivos/pdf/livro07.pdf>. Acessado em junho de 2014.

BRASIL. Ministério da Educação. Lei N. 9394 de 20 de dezembro de 1996. Estabelece as diretrizes e bases da educação nacional. Basília, 1996. Disponível em: <http://www. planalto.gov.br/CCIVIL_03/LEIS/L9394htm>. Acessado em junho de 2014.

BROUGĖRE, Gilles. Jogo e educação. Porto Alegre: Artes Médicas, 1998.

CASTELLANI FILHO, Lino. Educação Física no Brasil: a história que não se conta. Papirus Editora, 1988.

COLETIVO DE AUTORES. Metodologia do Ensino de Educação Física. São Paulo: Cortez, 1992.

CHIZZOTTI, Antônio. Pesquisa em ciências humanas e sociais/Antônio Chizzotti. 2. ed.- São Paulo: Cortez, 1998.- (Biblioteca da educação. Série 1. Escola; v.16).

CRESWELL, John. W. Projeto de pesquisa, métodos qualitativo, quantitativo e misto/ John W. Creswell: Tradução Magda Lopes. Conselho, supervisão e revisão técnica desta edição Dirceu da Silva. 3.ed. Porto Alegre: Armetd, 2010. 
GONZÁLEZ, Fernando. J. Projeto curricular e educação física: o esporte como conteúdo escolar. O fenômeno esportivo: ensaios crítico-reflexivos. Chapecó: Argos, 2006, 69-109.

HENRI, Wallon: uma concepção dialética do desenvolvimento infantil/Izabel Galvão. Petrópolis, RJ ; Vozes, 1995. - (Educação e conhecimento).

KUNZ, Elenor. (organizador) Brincar e Se-Movimentar: tempos e espaços de vida da criança. ljuí: Ed. Unijuí. 2015.

KUNZ, Elenor. Kinein: o movimento humano como tema. Kinein, Florianópolis, v. 1, n. 1, set./dez. 2000. Disponível em: <http://boletimef.org/biblioteca/2601/Kinein-o-movimentohumano-como-tema>. Acessado em junho de 2014.

KUNZ, Elenor. Transformação didático-pedagógica do esporte. 2 ed. Injuí: Injuí, 1998.

LIBÂNEO, José. C. Didática - São Paulo: Cortez,- (Coleção magistério, Série formação do professor). 2002.

VEIGA, IIma. P. A. A prática pedagógica do professor de didática/ Ilma Passos Alencastro Veiga. - Campinas, SP: Papirus, 1989.

VYGOTSKY, Lev. S. A formação social da mente: o desenvolvimento dos processos psicológicos superiores. $4^{\mathrm{a}}$ ed. São Paulo: Martins Fontes, 1991.

ZABALA, Antoni. A Prática Educativa: como ensinar. Porto Alegre: ArtMed, 1998. 


\section{THE LOOK OF PEDAGOGUE ABOUT PHYSICAL EDUCATION IN PRIMARY SCHOOL.}

ABSTRACT: The aim of this paper is to show, through a case study, discussions accomplished during subject of Physical Education and Human Move of Pedagogy Course/ UFSM from observations realized in Primary School at a public school of Santa Maria/ RS, which enabled to identify structure to Physical Education classes, enabling reflexions about planning and teaching practice in Physical Educations classes. Dates allowed to view that not always exist a consistent planning to classes, which create learning difficulties of contents.

Keywords: Physical Education. Teaching practice. Primary School.

\section{UNA MIRADA DESDE EL PEDAGOGO SOBRE LA EDUCACIÓN FISICA EN PRIMARIA}

Resumen: El objetivo de este trabajo es presentar, a través de un estudio de caso, las discusiones realizadas durante la asignatura de Educación Física y Movimiento Humano del grado de Licenciatura en Pedagogía/UFSM, a partir de observaciones realizadas en los años de primaria de una escuela de la red pública del municipio de Santa María/RS que han posibilitado identificar la estructura de las clases de Educación Física, posibilitando reflexiones acerca de la planificación y la práctica pedagógica en clases de Educación Física. Los datos permitieron constatar que no siempre ocurre una planificación consistente para las clases, lo que genera dificultades de aprendizaje de los contenidos.

Palabras clave: Educación Física. Práctica Pedagógica. Primaria. 